LBNL-54109

\title{
Black Carbon Emissions in the United Kingdom during the past four decades: An empirical analysis
}

\author{
T. Novakov ${ }^{*}$ and J. E. Hansen ${ }^{2}$ \\ ${ }^{1}$ Environmental Energy Technologies Division, Lawrence Berkeley National Laboratory, MS- \\ 70-180B, Berkeley, CA, 94720, USA. \\ ${ }^{2}$ NASA Goddard Institute for Space Studies, 2880 Broadway, New York, NY 10025, USA
}

\begin{abstract}
We use data from a unique 40-year record of 150 urban and rural stations in the "Black Smoke and $\mathrm{SO}_{2}$ Network" in Great Britain to infer information about sources of atmospheric black carbon (BC). The data show a rapid decline of ambient atmospheric BC between 1962 and the early 1990s that exceeds the decline in official estimates of BC emissions based only on amount of fuel use and mostly fixed emission factors. This provides empirical confirmation of the existence and large impact of a time-dependent "technology factor" that must multiply the rate of fossil fuel use. Current ambient BC amounts in Great Britain comparable to those in western and central Europe, with diesel engines being the principal present source. From comparison of $\mathrm{BC}$ and $\mathrm{SO}_{2}$ data we infer that current $\mathrm{BC}$ emission inventories understate true emissions in the U.K. by about a factor of two. The results imply that there is the potential for improved technology to achieve large reduction of global ambient BC. There is a need for comparable monitoring of $\mathrm{BC}$ in other countries.
\end{abstract}

Keywords: Black carbon, black smoke, emission trends, sources, technology factor,

*Corresponding author (tnovakov@lbl.gov) 


\section{Introduction}

Soot is among the most important of air pollutants. Soot is a particle-phase product of incomplete combustion of carbon containing fuels. It main components are black carbon (BC) and organic carbon (OC). Most studies of the human health effects of air pollution have not been composition specific, but there is evidence that tiny soot particles, which usually include toxic organic carbon and metals, are carcinogenic and among the most harmful pollutants (Künzli et al., 2000).

Black carbon (BC), the principal light-absorbing component of soot, arguably rivals methane for being the second largest contributor to global warming, causing a total forcing, including its indirect effects on snow and cloud albedos, of $0.8 \pm 0.4 \mathrm{~W} / \mathrm{m}^{2}$ (Hansen and Nazarenko, 2003). BC may affect regional climate; for example, it has been suggested that the heavy concentration of soot over China and India may be responsible for a trend toward increased flooding in the south and drought in the north (Menon et al., 2002). Soot reduces atmospheric transparency and visibility, by enough in India and China to reduce agricultural productivity an estimated $10-20 \%$ (Chameides et al., 1999) with additional productivity loss from soot deposited on plant leaves (Bergin et al., 2001). Soot is also esthetically displeasing as it is responsible for the brown appearance of urban hazes and soiling of buildings.

Soot in general and $\mathrm{BC}$ in particular have not received sufficient attention in measurements and analyses to define well their role in global climate change. The amount of $\mathrm{BC}$ in the atmosphere today is very uncertain. Sato et al. (2003) argued, from analysis of sunphotometer measurements at about 100 sites around the world, that global aerosol models understate black carbon absorption by a factor of 2-4, although they suggest that part of the observed absorption is due to enhancement from internal mixing (Chylek, 1988; Jacobson, 2000), rather than from underestimate of $\mathrm{BC}$ mass. Knowing the variation of $\mathrm{BC}$ during the past century is needed to interpret climate change. Thus data that shed light on the amount of $\mathrm{BC}$ in the air today and historical changes of $\mathrm{BC}$ amount would be valuable.

$\mathrm{BC}$ is a product of incomplete combustion. Unlike $\mathrm{SO}_{2}$ emissions, which principally depend on the mass of fuel burned and its sulfur content, $\mathrm{BC}$ emissions are governed by both the fuel consumed and combustion technology. For example, the BC emission factor (emitted BC mass per unit mass of fuel) for coal combustion in inefficient household stoves can be orders of 
magnitude greater than the emission factor for efficient coal burning in large power plants. Consequently, the aerosol optical properties (light absorption and scattering) depend on the relative contributions of emissions from inefficient and efficient fuel utilization sectors.

During the past century coal utilization in industrialized countries has shifted from residential, commercial and industrial sectors to the electric power generation sector. Since BC emissions from the former are higher than from the latter, $\mathrm{BC}$ emissions in these countries decreased as coal use by the non-power generation sectors decreased. In most industrializing countries, however, fossil fuel emissions increased more nearly in concert with fuel consumption because the proportion of fuel use by different sectors did not change appreciably. Novakov et al. (2003) estimated effects of changes in fuel use on BC emissions during the past century using sector-segregated fossil fuel consumption data and published emission factors.

Here we present empirical evidence for the effect of changing fuel utilization on measured $\mathrm{BC}$ concentrations, compare these results with expectations based on emission inventories, and discuss potential ramifications. Our analysis employs data generated by the "Black Smoke and $\mathrm{SO}_{2}$ Network" that has been operating continuously since 1962 at more than 150 urban, periurban and rural monitoring sites throughout much of the U.K. (Loader et al., 2003). These data, consisting of both measured concentration and estimated BC emissions, are notable in the sense that they cover four decades characterized by large changes in fossil fuel utilization.

Section 2 specifies the sources of the data that we employ. Section 3 presents the data with a qualitative discussion of its temporal variations. In Section 4 we obtain more quantitative inferences from the relative amounts and changes of $\mathrm{BC}$ and $\mathrm{SO}_{2}$. We discuss implications of the analyses in Section 5.

\section{Data sources}

Measurement sites in the Black Smoke (BS) and $\mathrm{SO}_{2}$ Network reporting in 2001 are shown in Fig. 1, which illustrates the mean $\mathrm{SO}_{2}$ measured for that annual period (Loader et al. 2003). The majority of sites are urban or peri-urban, although several are in rural areas. Most of our analysis refers to annual $\mathrm{BS}$ and $\mathrm{SO}_{2}$ concentrations averaged over all monitoring sites, and to emission inventories of these species for the entire U.K. (sources of data are summarized in Table 1). Note that we used two BS data sets. An older one covering the 1962-1970 period and a recent one for 1970-1999. The annual averaging reduces variability associated with weather 
fluctuations and noise in the data. The national average further reduces noise, but we present examples of local data for an urban site and a rural site to show the effect of distance from major sources.

BS is determined by an optical reflectance method that measures the darkness of stain on white filter paper through which the particle-laden air is drawn (Bailey and Clayton, 1982). The measured the concentrations of light-absorbing aerosols in units of $\mu \mathrm{g}(\mathrm{BS}) \mathrm{m}^{-3}$ In the following we convert these units to more commonly used units of $\mu \mathrm{g}(\mathrm{BC}) \mathrm{m}^{-3}$ via the relationship $\mathrm{BC}=$ 0.23 BS obtained by (Erdman et al., 1993). We note that a different relationship, BC $=0.13 \mathrm{BS}$, was obtained in an older study (Edwards et al., 1983). Our conclusions, however, would not change if only BS was used.

We express $\mathrm{SO}_{2}$ concentrations and emissions in $\mu \mathrm{g}(\mathrm{S}) \mathrm{m}^{-3}$ and $\mathrm{Tg}(\mathrm{S}) \mathrm{yr}^{-1}$, respectively. We denote $\mathrm{SO}_{2}$ emissions as $\mathrm{S}$, ambient gaseous $\mathrm{SO}_{2}$ as $\mathrm{S}_{\mathrm{g}}$, and total ambient sulfur $\mathrm{S}_{\mathrm{t}}$ as the sum of $\mathrm{S}_{\mathrm{g}}$ and particle phase (sulfate) $\mathrm{S}_{\mathrm{p}}$. BC values are derived from BS data as discussed above.

\section{Interpretation of $\mathrm{BC}$ historical trends}

Our analysis is based on the expectation that average long-term ambient mass concentrations of $\mathrm{BC}$ and $\mathrm{SO}_{2}$, in a source-dominated region such as the U.K., should be proportional to the source strengths of these species, if the monitoring sites are affected by all UK sources. This assertion is supported by Handley and Tuomi (2001) who have shown that the gradients in $\mathrm{SO}_{2}$ concentration trends do not differ greatly at site located at different distances from the main U.K. sources. Furthermore, network averaged annual BC concentrations are highly correlated with BC concentrations at Didcot $\left(\mathrm{R}^{2}=0.851\right)$ and Manchester $\left(\mathrm{R}^{2}=0.957\right)$. Also the trends in $\mathrm{BC}$ gradients at the two sites are quite similar to the trend in network averaged BC. The temporal and spatial variations of emissions and ambient concentrations, discussed below, are consistent with this expectation. Although our interest is in $\mathrm{BC}$, we present $\mathrm{SO}_{2}$ measurements in this section as well, because we use the $\mathrm{SO}_{2}$ amounts in section 4 to constrain estimates of the $\mathrm{BC}$ source strength.

Time series of BC and $\mathrm{S}$ annual emissions in the U.K., as reported by the data sources in Table 1, are shown in Fig. 2a. The annual means of the measured BC and $\mathrm{S}_{\mathrm{g}}$ ambient concentrations, averaged over the Black Smoke and $\mathrm{SO}_{2}$ Network sites, are shown in Fig. $2 \mathrm{~b}$. The emissions and ambient concentrations of both species decrease almost monotonically 
throughout the period of record. BC emission estimates in Fig. 2 (from U.K. National Atmospheric Emission Inventory - NAEI) are based on fuel use statistics with the assumption that $\mathrm{BC}$ emission factors (per unit mass of fuel) are constant throughout the period for each fuel use sector (power plant, industry, residential and diesel). Diesel emission factors in the period 1992-1999 assumed to decrease because of improving engine technologies [http://www.aeat.co.uk/netcen/airqual/statbase/emissions/bs-99.html].

Emissions and ambient amounts of both $\mathrm{BC}$ and $\mathrm{S}_{\mathrm{g}}$ declined dramatically over the past four decades in the U.K. Note that the fractional decline of $\mathrm{BC}$ was more rapid early in the period, while the fractional decline of $\mathrm{S}_{\mathrm{g}}$ was more rapid late in the period. This is consistent with the emphasis on soot reduction that followed devastating "London smog" problems of the 1950s and the emphasis on reducing acid rain in recent decades.

Fig. 3a shows the $\mathrm{BC}$ ambient amount as a function of $\mathrm{BC}$ emissions, while Fig. $3 \mathrm{~b}$ is the analogous graph for $\mathrm{S}_{\mathrm{g}}$. In both graphs the plotted points go from the earliest date (1962) in the upper right to the most recent date in the lower left. We note that $\mathrm{S}$ emissions are about 10 times greater than $\mathrm{BC}$ emissions, according to the emission inventories (Fig. 2a). Yet Fig.2b suggests that measured atmospheric amounts of gaseous sulfur $\left(\mathrm{S}_{\mathrm{g}}\right)$ are only about three times larger than measured ambient BC. This inconsistency suggests that BC emissions may be underestimated. We explore this quantitatively in Section 4, where we consider other factors that may affect interpretation of the measurements

In Fig. 3 it is apparent that both $\mathrm{BC}$ and $\mathrm{S}_{\mathrm{g}}$ decrease more rapidly than linearly with emissions. Reduction of $\mathrm{S}_{\mathrm{g}}$ is expected because of decreasing coal use and possibly reduced sulfur content of fuels. The reduction of $\mathrm{BC}$ emissions and concentrations is caused principally by decreased use of coal. Although $\mathrm{BC}$ emissions from coal were steadily declining, leveling off of $\mathrm{BC}$ concentrations in recent years has been caused by increasing use of diesel fuel, as illustrated below.

Interpretation of changing $\mathrm{BC}$ ambient amount is aided by examination of the temporal change of emissions as a function of sector and the geographical variation of emissions and ambient amounts. Fig. 4 shows fuel consumption in the U.K. in Tg of fuel per year for four sectors, "power plant", "total industry" and "residential" for coal and diesel fuel, according to the International Energy Agency (IEA, 2000). Sector-segregated BC emissions for the U.K. show that the "industry" and "residential" coal sectors together with diesel use account for almost $90 \%$ 
of British BC emissions (http://www.aeat.co.uk/netcen/airqual/statbase/emissions/bs-99.html). This is because $\mathrm{BC}$ emission from power plants is assumed to be negligible, while emission factors for industrial and residential coal use are estimated as $0.23 \mathrm{~g} / \mathrm{kg}$ and $9.2 \mathrm{~g} / \mathrm{kg}$, respectively, and as $1.9 \mathrm{~g} / \mathrm{kg}$ for diesel (Table 2). Diesel fuel has a moderate estimated emission factor and contributed relatively little to $\mathrm{BC}$ emissions until the past two decades, when use rose while coal consumption continued to decline. The primary source of $\mathrm{BC}$ through most of the period of record is thus residential and industrial coal burning. The decline in $\mathrm{BC}$ ambient amounts in Fig. 3a, more rapid than the decline of fuel amount, must reflect technology change in the dominant residential sector, which is consistent with a known trend from use of individual stoves to less polluting central heating. We note that the primary source of atmospheric BC, or soot, in Great Britain today is diesel fuel, which is very unlike the situation in prior decades when coal burning was the primary source of soot. The long range transport from the European continent, however, although undoubtedly present could be ignored for the purpose of this paper. For example Derwent et al.(2001), concluded that transported mean BC concentrations transported from Europe during 1995-1998 are $0.69 \mu \mathrm{g} \mathrm{m}^{-3}$. This should be compared with a network average $\mathrm{BC}$ concentration of $2.2 \mu \mathrm{g} \mathrm{m}^{-3}$ the 1995-1998 period (or 3 times higher).

Fig. 5 compares ambient $\mathrm{BC}$ concentrations measured at urban (Manchester) and rural (Didcot) sites, as a function of national BC emissions (data source in Table 1). The urban BC amount is not only larger, it also decreases more rapidly with time. The urban $\mathrm{BC}$ concentration decreases more steeply than linearly with estimated emissions, when, as in Fig. 3, there is essentially no "technology factor" correction included in the emissions estimate. The ambient $\mathrm{BC}$ amount in Manchester, dominated by local sources, is especially large in winter, i.e., during the heating season. These facts support the conclusion that $\mathrm{BC}$ emissions have decreased because of the decrease in coal consumption and because the technology factor in residential sector caused a decrease of the $\mathrm{BC}$ emission factor over time. In the rural Didcot location, distant from large sources, the $\mathrm{BC}$ amount is not only smaller, but it also decreases more slowly as a function of reported national emissions. It is possible that the rural $\mathrm{BC}$ amount is influenced more by the diesel source, which has increased over time, or other sources that have not decreased as rapidly as residential and industrial coal burning.

Ambient annual BC concentrations in the 1998-2000 period averaged about $1.8 \mu \mathrm{g} \mathrm{m}^{-3}$. This value is comparable to the range $0.6 \mu \mathrm{g} \mathrm{m}^{-3}$ to $1.6 \mu \mathrm{g} \mathrm{m}^{-3}$ recently measured in rural 
Hungary and Portugal (Zappoli et al., 1999; Castro et al., 1999). (Note that the U.K. concentrations are derived using $\mathrm{BC}=0.23 \mathrm{BS}$; using the factor 0.13 reported by Edwards et al. (1983) would lower the ambient BC to about $1 \mu \mathrm{g} \mathrm{m}^{-3}$.) Obviously, the tendency of ambient BC amount to level out in recent years should not be interpreted as an indication that $\mathrm{BC}$ amounts in Great Britain are approaching a clean atmospheric "background" level. Even at the rural (Didcot) site the $\mathrm{BC}$ amount is $\sim 1000 \mathrm{ng} / \mathrm{m}^{3}$, which is typical of moderate to heavily polluted regions in middle latitudes of the Northern Hemisphere and about twice as great as the typical BC amount in the well-studied Arctic Haze episodes in the 1980s (Hansen and Novakov, 1989). Although the "black smoke" record is not the most precise measurement of $\mathrm{BC}$, the measured $\mathrm{BC}$ amount clearly falls in the category of moderately polluted continental air.

The $\mathrm{BC}$ data by themselves illustrate that the large decrease in ambient $\mathrm{BC}$ amounts, which has occurred especially in urban areas, is a product of both changing fuel use and combustion technology. We suggest below that more quantitative statements can be made by comparison of the $\mathrm{BC}$ and $\mathrm{SO}_{2}$ records, somewhat analogous to the comparison of $\mathrm{BC}$ and $\mathrm{CO}$ data by Dickerson et al. (2002). Specifically, in the following section we use the ratio of $\mathrm{BC}$ to $\mathrm{SO}_{2}$ to evaluate the emission factor for $\mathrm{BC}$, which is much more poorly known than the emission factor for $\mathrm{SO}_{2}$.

\section{Evaluation of $\mathrm{BC}$ emission factor}

$\mathrm{BC}$ emissions to the atmosphere are highly uncertain. $\mathrm{BC}$ emissions are estimated from fuel consumption data and assumed sector-specific emission factors, but emission factors are not well measured, often being uncertain by a factor of two or even more (Bond et al., submitted to J. Geophys. Res., 2003; Cooke et al., 1999). It has been argued that global BC distributions derived from typical emission factors yield much less absorption of sunlight than observed by a widespread network of sun photometers (Sato et al., 2003), suggesting that either BC emission factors are underestimated or there are additional $\mathrm{BC}$ sources not included in current aerosol models. However, Bond et al. (submitted to J. Geophys. Res., 2003) argue that reexamination of emission factors suggests that the emission factors are generally overestimated, not underestimated. Thus there is a need for an alternative evaluation of $\mathrm{BC}$ emission factors.

The Black Smoke and $\mathrm{SO}_{2}$ Network, with its simultaneously measured $\mathrm{BC}$ and $\mathrm{SO}_{2}$ measurements, provides an opportunity for an indirect assessment of the mean $\mathrm{BC}$ emission 
factor in Great Britain. This assessment depends on the assumption that uncontrolled SO2 emissions are relatively well known, because they depend principally on amount of fuel consumed and the sulfur content of fuels. A complication is caused by the fact that the Black Smoke and $\mathrm{SO}_{2}$ Network measures only $\mathrm{SO}_{2}$ gas $\left(\mathrm{S}_{\mathrm{g}}\right)$, while the sulfur produced in burning of fossil fuels resides in both $S_{g}$ and $S_{p}$ (sulfate particles). We handle this uncertainty by considering an appropriate range for the uncertain sulfate fraction of total sulfur.

Fig. 6a plots BC emissions vs. S emissions, with both of these based on the estimates from the sources specified in Table 1. Fig. 6b similarly compares the measured ambient amounts of $\mathrm{BC}$ and $\mathrm{S}_{\mathrm{g}}$ averaged over the Black Smoke and $\mathrm{SO}_{2}$ Network. The $\mathrm{BC}$ and $\mathrm{S}_{\mathrm{g}}$ ambient amounts are well correlated, with both of them decreasing in Great Britain over the entire period, but their relationship changed in about 1975. Between 1962 and 1975 BC decreased by a factor 6.5 while $\mathrm{S}_{\mathrm{g}}$ decreased by a factor 3.1. Between 1975 and $2000 \mathrm{BC}$ decreased by a factor 2.3 and $\mathrm{S}_{\mathrm{g}}$ decreased by a factor 3.8. This change in $\mathrm{BC}$ vs. $\mathrm{SO}_{2}$ coincides with the change in the fraction of non-power coal use (Fig. 4). For example, in 1963 coal consumed by the residential sector accounted for $65 \%$ of coal used by the electric power sector. By 1975 this fraction had decreased to $14 \%$, and it decreased further through the remainder of the period considered.

The rapid $\mathrm{BC}$ reduction prior to 1975 is related to the UK clean air act of 1958 with consequent emphasis on reducing coal smoke emissions from domestic and industrial sectors. Since about 1975 there has been more emphasis on reducing acid rain and thus on the sulfur content of fuels. $\mathrm{BC}$ and $\mathrm{S}_{\mathrm{g}}$ both decline during both periods as most actions to reduce one constituent also reduce the other, but there seems to have been a detectable change of emphasis in the late 1970s.

Fig. 7a shows the ratio of emissions, BC/S, in the U.K. National Atmospheric Emission Inventory (NAEI), and the ratio of ambient atmospheric amounts, $\mathrm{BC} / \mathrm{S}_{\mathrm{g}}$, measured by the Black Smoke and $\mathrm{SO}_{2}$ Network (Fig. 7b) as a function of time. The ratio for the ambient atmospheric amounts is about three times larger than the ratio of estimated emissions. The larger ratio in the atmosphere could be due in part to the fact that a fraction of the emitted sulfur has been oxidized into sulfate particles $\left(\mathrm{S}_{\mathrm{p}}\right) . \mathrm{S}_{\mathrm{p}} / \mathrm{S}_{\mathrm{g}}$ has been measured at several urban (Nicholson and Davies, 1990) and rural (Irvin et al., 2002) sites in the U.K. as $0.14 \pm 0.03$ and $0.39 \pm 0.18$, respectively. The greater degree of conversion to particles at larger distances from the principal sources is expected. 
Fig. $7 \mathrm{~b}$ shows the range of $\mathrm{BC} / \mathrm{S}$ with $\mathrm{S}$ corrected to include sulfur in particle form for the measured range of $\mathrm{S}_{\mathrm{p}} / \mathrm{S}_{\mathrm{g}}$. Most of the stations in the Black Smoke and $\mathrm{SO}_{2}$ Network are urban and peri-urban, so the 0.14 correction is probably the more appropriate. However, even at the extreme $\mathrm{S}_{\mathrm{p}} / \mathrm{S}_{\mathrm{g}}=0.39$ the measured atmospheric $\mathrm{BC} / \mathrm{S}$ ratio is about double the ratio for estimated emissions. We believe this indicates that $\mathrm{BC}$ emissions are underestimated. However, let us consider alternative explanations. One possibility is that the ratio $\mathrm{S}_{\mathrm{p}} / \mathrm{S}_{\mathrm{g}}$ is even larger than measured at rural sites. However, the required $\mathrm{S}_{\mathrm{p}} / \mathrm{S}_{\mathrm{g}}$ ratio of 2 or larger is implausible for a small source-dominated region such as Great Britain. Another possibility is that the $\mathrm{S}$ emissions escape measurement by being emitted at high altitudes by tall stacks and then wafted out of the country. This explanation, however, would require that escape of $\mathrm{S}$ is largest at the beginning of the period of record, when tall stacks were least common.

We conclude that the most likely explanation is that the $\mathrm{BC}$ emission inventory underestimates actual $\mathrm{BC}$ emissions. This seems to be a feasible explanation given the broad spread in published $\mathrm{BC}$ emission factors. Table 2 gives examples of emission factors that have been used in estimating BC emissions in the U.K. Apparently there is a good deal of uncertainty in BC emission factors, as has been emphasized by Cooke et al. (1999) and Bond et al. (submitted to J. Geophys. Res., 2003). For example, it seems possible that the NAEI emission factor for industrial coal use could be substantially too small. There could be other BC sources that are not included in the inventories. However, the fact that $\mathrm{BC}$ ambient amounts declined rapidly as the known sources declined implies that the identified sources are the main sources, and it thus suggests that the emission factors have been underestimated.

\section{Summary and implications}

Aerosol filter samples obtained by the Black Smoke and $\mathrm{SO}_{2}$ Network and the optical reflectance measurements on the filters yield four-decades-long consistent record on $\mathrm{BC}$ and $\mathrm{SO}_{2}$ concentrations. The measurement record is supplemented by the $\mathrm{BC}$ and $\mathrm{SO}_{2}$ emission inventories covering the same period as the measurements. This combined record contains a valuable history of $\mathrm{BC}$ change in the United Kingdom over the past four decades.

The data show that the ambient atmospheric amount of BC in the United Kingdom declined steadily during the past 40 years, although possibly leveling off during the past several years. The decline was more rapid than the decrease in BC-producing fuel use, even with the 
assumption that fossil fuel power plants emit negligible BC. This confirms the existence a timedependent "technology factor" that reduces BC emissions for a given fuel amount. There is still substantial use of coal in the United Kingdom, but BC emissions have been reduced.

We infer from the Black Smoke and $\mathrm{SO}_{2}$ data that current $\mathrm{BC}$ emissions in Great Britain are underestimated by about a factor of two. The underestimation at earlier times was even larger, about a factor of three or more in the 1960s. These values are based on an assumption that the average ratio of $S$ in sulfate particles to $S$ in gaseous form is about 0.25 for the network of measuring stations, which we suggest yields a conservative estimate for the amount of BC. As black smoke measurements are continued, it would be valuable to have them supplemented with high-precision composition-specific analytical studies. This would make the unique long records of the Black Smoke and $\mathrm{SO}_{2}$ Network even more valuable.

We estimate the current $\mathrm{BC}$ amount for the Black Smoke and $\mathrm{SO}_{2}$ Network locations as approximately 1-2 $\mu \mathrm{g} \mathrm{m}^{-3}$. Thus despite a substantial decline over the past four decades, the air in Britain still has moderate to heavy BC pollution. The measured BC has almost leveled off in the past several years, possibly because increasing diesel fuel emissions have compensated for declining coal emissions.

Thus there are two ways to view this record. From one perspective, the large decrease of $\mathrm{BC}$ over the first three decades of the record shows the potential for technology to reduce $\mathrm{BC}$ from coal emissions. On the other hand, the data also tell a cautionary tale, as they suggest that ambient BC amounts are leveling off and diesel emissions are increasing. Diesel soot emissions include organic carbon and metals (Wang et al., 2003) and have been explicitly implicated in health effects (Künzli et al., 2000). Future trends of BC could go either direction, as there is increasing use of diesel fuel for transportation vehicles, but also the potential for technological improvements that reduce emissions. The actual trend will have implications for climate and other effects, as well as human health.

Despite its practical importance, the amount of BC in the global atmosphere is very uncertain. This gross ignorance needs to be rectified for the sake of understanding the practical effects of soot today as well as for monitoring future changes in atmospheric amounts. We have found that even simple inexpensive measurements, such as the filter samples of the Black Smoke and $\mathrm{SO}_{2}$ Network in the United Kingdom, yield a valuable record, but modern analytical 
techniques could add important composition information. Long-term monitoring with standardized procedures is needed on a more global basis. It is well justified for the sake of providing information that will be needed by decision-makers as the multiple effects of soot are understood better and as it becomes desirable to document progress in reducing atmospheric amounts.

Acknowledgments. This was supported by the Director, Office of Science, Office of Biological and Environmental Research, U.S. Department of Energy and National Aeronautical and Space Administration. We thank A. Loader for information regarding $\mathrm{SO}_{2}$ measurement methods employed by the network.

\section{References}

Bailey, D.L.R., Clayton, P., 1982. The measurement of suspended particle and total carbon concentrations in the atmosphere using standard smoke shade methods. Atmospheric. Environment 16, 2683-2690..

Bergin, M.H., Greenwald, R., Xu, J., Berta, Y., Chameides, W.L., 2001. Influence of aerosol dry deposition on photosynthetically active radiation available to plants: A case study in the Yangtze delta region of China. Geophysical Research Letters 28, 3605-3608.

Castro, L.M.,. Pio, C.A., Harrison, R.M., Smith, D.J.T., 1999. Carbonaceous aerosols in urban and rural European atmospheres: estimation of secondary organic carbon concentrations. Atmospheric Environment 31, 2771-2781.

Chameides, W.L., Yu, H., Liu, S.C., Bergin, M., Zhou, X., Mearns, L., Wang, G., Kiang, C.S., Saylor, R.D., Luo, C., Huang, Y. Steiner, A., Giorgi., F.,1999. Case study of the effects of atmospheric aerosols and regional haze on agriculture: An opportunity to enhance crop yields in China through emission controls? Proceedings of National Academy of Sciences 96, 13626-13633..

Chylek, P., Srivastava, V., Pinnick, R.G., Wang, R.T., 1988. Scattering of electromagnetic waves by composite spherical particles: experiment and effective medium approximations. Applied Optics 27, 2396-2404..

Cooke W. F., Liousse, C., Cachier, H., Feichter, J., 1999. Construction of a $1^{\circ} \mathrm{C}{ }^{\circ} \mathrm{C}$ fossil fuel emission data set for carbonaceous aerosol and implementation in the ECHAM4 model. Journal of Geophysical Research 104, 22137-22162. 
Derwent, R.G., Ryall, D.B., Jennings, S.G., Spain, T.G., Simmonds, P.G., 2001. Black carbon aerosol and carbon monoxide in European regionally polluted air masses at Mace Head, Ireland during 1995-1998. Atmospheric Environment 35, 6371-6378.

Edwards, J.D., Ogren, J.,. Weisss, R.E.,. Charlson, R.J., 1983. Particulate air pollutants: a comparison of British "Smoke" with optical absorption coefficient and elemental carbon concentration. Atmospheric Environment 17, 237-2341.

Erdman, A., Israel, G.W., Ulrich, E., 1993. Comparative measurements of atmospheric elemental carbon using the British Black Smoke sampler and a thermal carbon analyzer (in German). Staub, 53, 187-191.

Hadley, A., Toumi, R., 2002. Non-linearities between atmospheric sulphur and sulphur emissions. Water, Air, and Soil Pollution 140, 279-295.

Hansen, A.D.A., Novakov, T., 1989. Aerosol black carbon measurements in the Arctic haze during AGASP-II. Journal of Atmospheric Chemistry 9, 347-361.

Hansen, J., Nazarenko, L., 2003. Soot climate forcing via snow and ice albedos. Proceedings of National Academy of Science 101, 423-428.

IEA, 2000, World Energy Statistics and Balances, International Energy Agency, Diskette Service, Paris.

Irwin, J.G., Campbell, G., Vincent, K., 2002. Trends in sulphate and nitrate wet deposition over the United Kingdom: 1986-1999. Atmospheric Environment 36, 2867-2979.

Jacobson, M.Z., 2000. A physically-based treatment of elemental carbon optics: implications for global direct forcing of aerosols. Geophysical Research Letters 27, 217-220..

Künzli, N., Kaiser, R., Medina, S., Studnicka, M., Chanel, O., Filliger, P., Herry, M., Horak, F., Puybonnieux-Texier, V., Quenel, P., Schneider, J., Seethaler, R., Vergnaud, J.C., Sommer, H., 2000. Public-health impact of outdoor and traffic-related air pollution: a European assessment. The Lancet 356, 795-801.

Lefohn, A.S., Husar, J.D., Husar, R.B., 1999. Estimating historical anthropogenic global sulfur emission patterns for the period 1950-1990. Atmospheric Environment 33, 3435-3444.

Loader, A., Mooney, D., Coghlan, M., 2003. UK Smoke and Sulphur Dioxide Network 2001, Report AEAT/ENV/R/1358 Issue 1, Netcen, Abingdon, Oxon, UK.

Menon, S., Hansen, J., Nazarenko. L., Luo, Y., 2002. Climate effects of black carbon aerosols in China and India. Science, 297, 2250-2253. 
Nicholson, K.W., Davies, T.D., 1990. Sulphate in atmospheric particulate at five sites in Norwich (U.K.): use of National Survey archive filters. Atmospheric Environmet.24B, 329334.

Novakov, T., Ramanathan, V., Hansen, J. E. , Kirchstetter, T. W., Sato, M., Sinton, J. E.,.

Sathaye, J. A., 2003. Large historical changes of fossil-fuel black carbon aerosols.

Geophysical Research Letters 30(6), 1324, doi:10.1029/2002GL016345.

Sato, M., Hansen, J., Koch, D., Lacis, A., Ruedy, R., Dubovik, O., Holben, B., Chin, M., Novakov, T., 2003. Global atmospheric black carbon inferred from AERONET. Proceedings of National Academy of Sciences 100, 6319-6324.

Streets, D.G., Gupta, S., Waldhoff, S.T, Wang, M.Q., Bond, T.C., Yiyun, B., 2001. Black carbon emissions in China. Atmospheric Environment 35, 4281-4296.

Wang, Y.F.,. Huang, K.L., Li, C.T., .Mi, H.H., Luo, J.H., Tsai, P.J., 2003. Emissions of fuel metals content from a diesel vehicle engine. Atmospheric Environment 37, 4637-4643.

WSL, 1972. National Survey of Air Pollution 1962-1971, Warren Spring Laboratory Dept. of Trade and Industry, London.

Zappoli, S., Andracchio, A.,. Fuzzi, S.,. Facchini, M.C., Gelencsér, A., Kiss, G., Krivácsy, Z., Molnár, Á., Mészáros, E., Hansson, H.-C.,. Rosman, K., Zebühr, Y., 1999. Inorganic, organic and macromolecular components of fine aerosol in different areas of Europe in relation to their water solubility. Atmospheric Environment 33, 2722-2743. 
Table 1. Types and sources of data

\begin{tabular}{lll}
\hline Data & Period & Reference \\
\hline $\mathrm{SO}_{2}$ and $\mathrm{BC} *$ & $1962-2001$ & http:/www.environment- \\
concentration & & agency.gov.uk/commondata/103608/fig3_ \\
& & so2_data.txt \\
& http://www.airquality.co.uk/archive/index. \\
& php \\
& & Lefohn et al. (1999) \\
$\mathrm{SO}_{2}$ emission & $1962-1990$ & http:/www.defra.gov.uk/environment/stat \\
$\mathrm{SO}_{2}$ emission & $1990-2000$ & istics/des/index.htm \\
& & Warren Spring Laboratory (1972) \\
$\mathrm{BC}^{*}$ emissions & $1962-1970$ & http:/www.aeat.co.uk/netcen/airqual/statb \\
$\mathrm{BC}^{*}$ emissions & $1970-1999$ & ase/emissions/bs-99.html \\
& &
\end{tabular}

* $\mathrm{BC}$ values derived from $\mathrm{BS}$ data (See text).

Table 2.

Comparison of $\mathrm{BC}$ emission factors $(\mathrm{g} / \mathrm{kg})$ ranges used for U.K. with other compilations.

\begin{tabular}{llll}
\hline Sector & NAEI* & Cooke et al. (1999) & Streets et al. (2001)** \\
\hline Coal, Domestic & $9.2-5.2$ & $4.6-2.8$ & $3.7-20$ \\
Coal, Industry & $0.23-0.13$ & $1.0-0.2$ & $0.003-0.02$ \\
Diesel & $1.9-1.1$ & $10-2.0$ & $1.1-2.5$
\end{tabular}

* BC values derived from BS data reported by U.K. National Atmospheric Emission Inventory (See text).

** Central and high values 


\section{Figure captions}

Fig. 1. Measurement sites of the UK Smoke and SO2 Network in 2001. The concentrations shown correspond to mean net acidity expressed as $\mathrm{SO}_{2}$ equivalent. From Loader et al., (2003), reproduced with permission.

Fig. 2. (a) $B C$ and $S_{g}$ emissions for the U.K., (b) $B C$ and $S_{g}$ mean ambient amounts for the network..

Fig. 3. $\mathrm{BC}$ and $\mathrm{S}_{\mathrm{g}}$ measured ambient amounts, averaged over the network, as a function of national emissions.

Fig. 4. Fuel consumption in Britain by sector, for sectors [IEA, 2000] that together contribute about $90 \%$ of estimated $\mathrm{BC}$ emissions.

Fig. 5. Ambient $\mathrm{BC}$ amounts measured at urban (Manchester) and rural (Didcot) locations, as a function of national emissions.

Fig. 6. (a) BC emissions vs. $\mathrm{S}$ emissions, and (b) BC ambient concentration vs. $\mathrm{S}_{\mathrm{g}}$ ambient concentration.

Fig. 7. (a) $\mathrm{BC} / \mathrm{S}$ ratio in estimated emissions and in ambient atmospheric concentrations measured at the Black Smoke and $\mathrm{SO}_{2}$ Network, (b) the same as Fig. 7a, but with the ambient $\mathrm{S}$ corrected to include sulfur in particle form, for the measured range $\mathrm{S}_{\mathrm{p}} / \mathrm{S}_{\mathrm{g}}=0.14$ to 0.39 . 


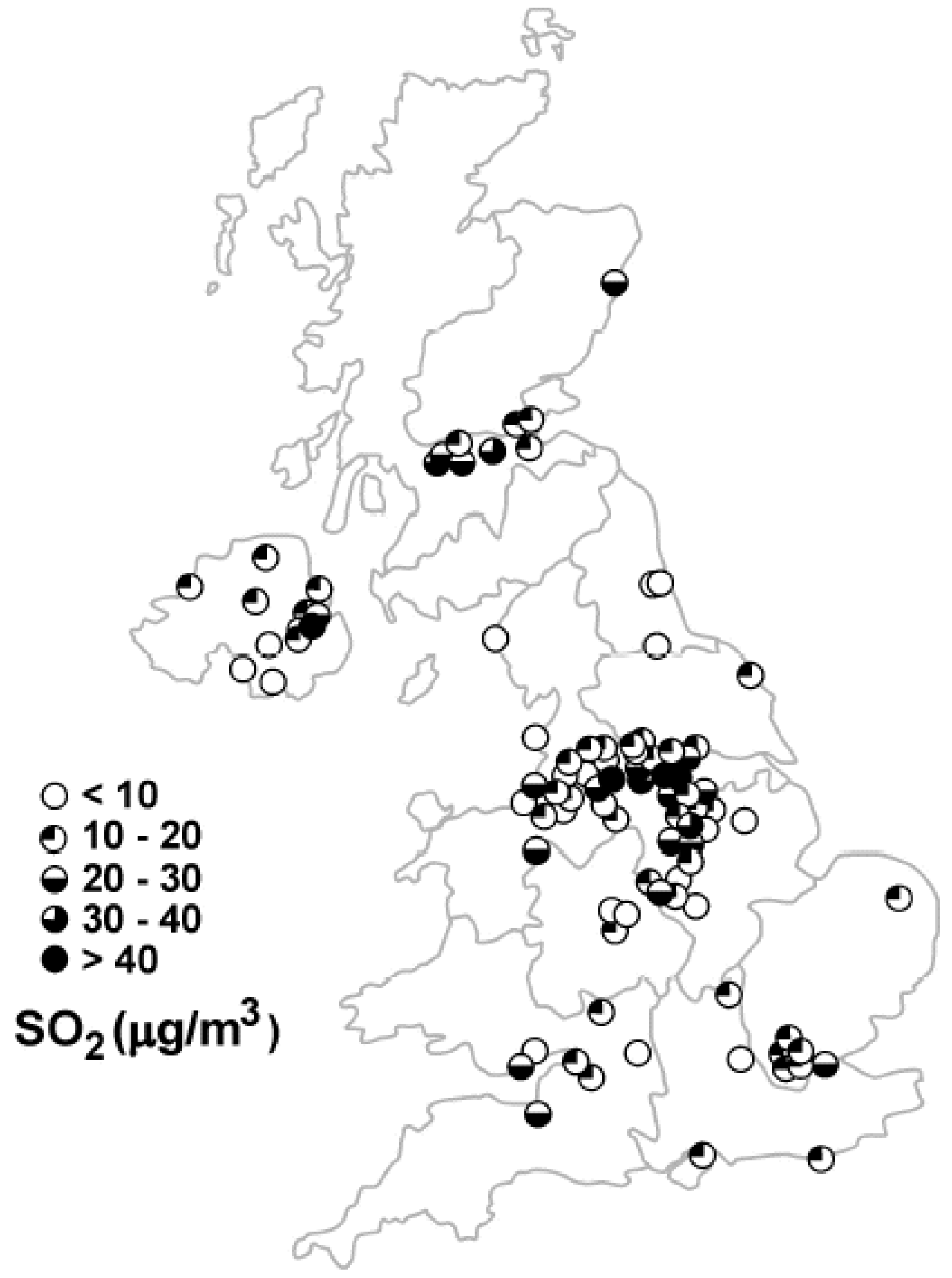

Fig. 1 

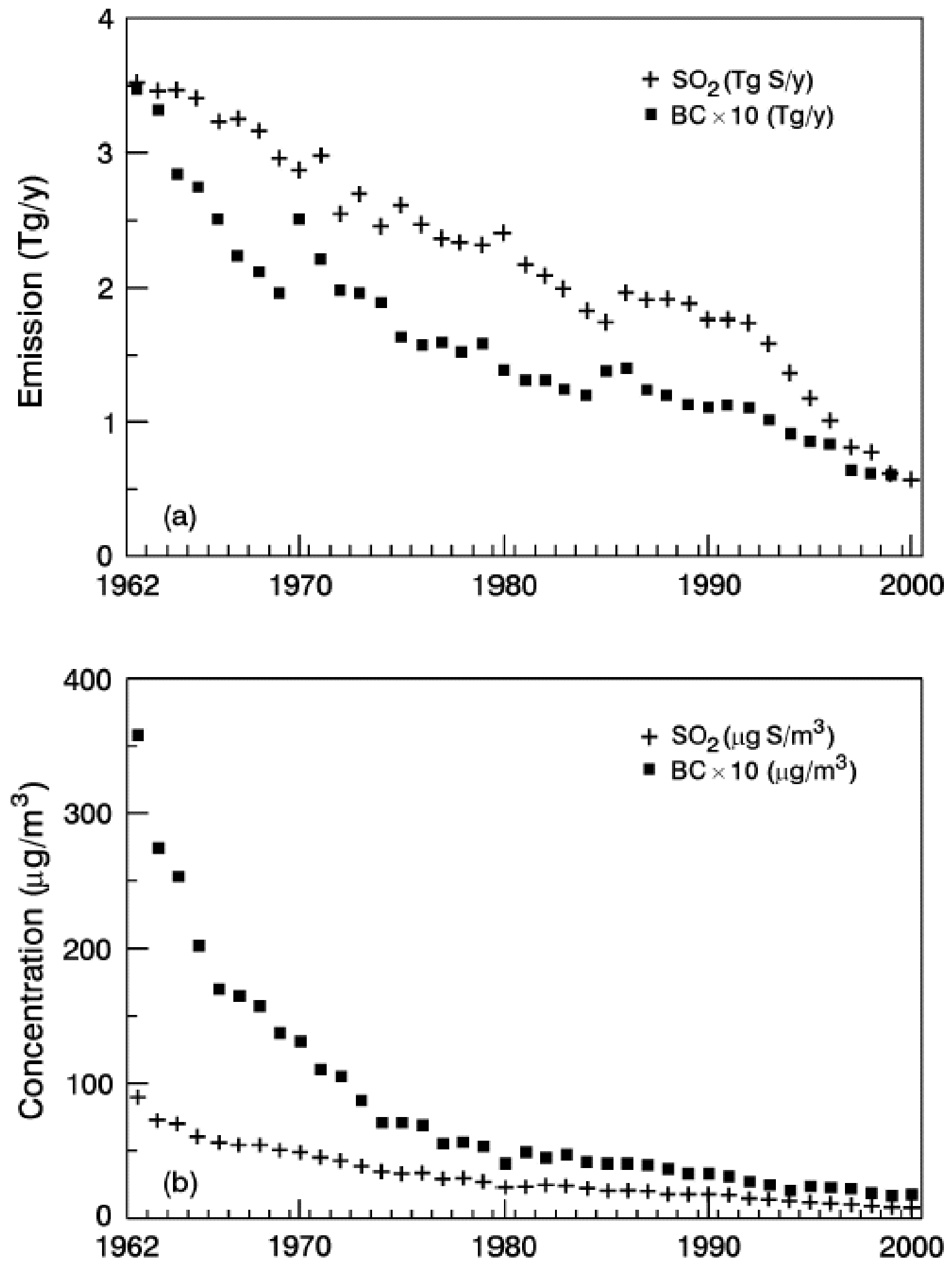

Fig. 2 

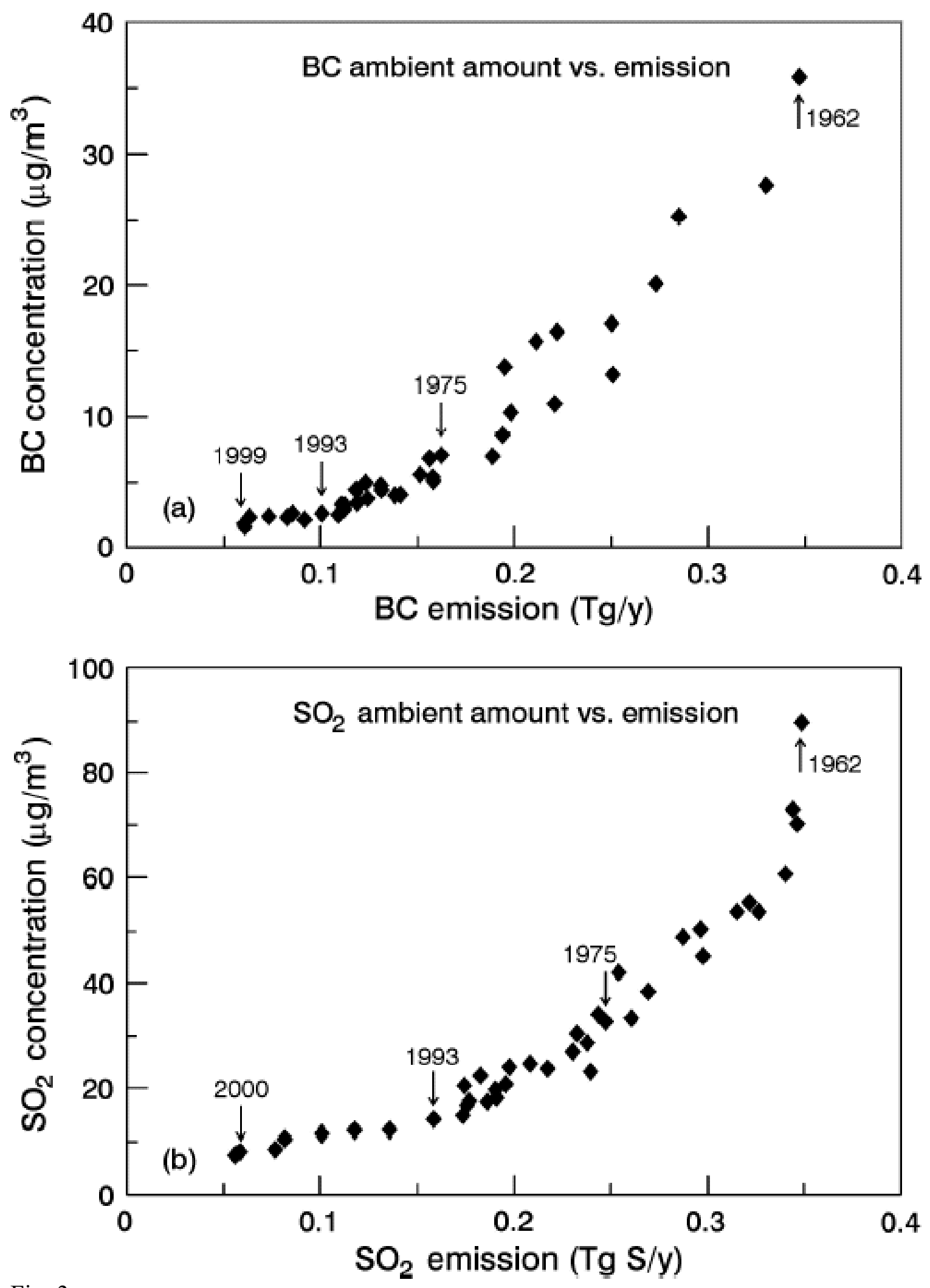

Fig. 3 


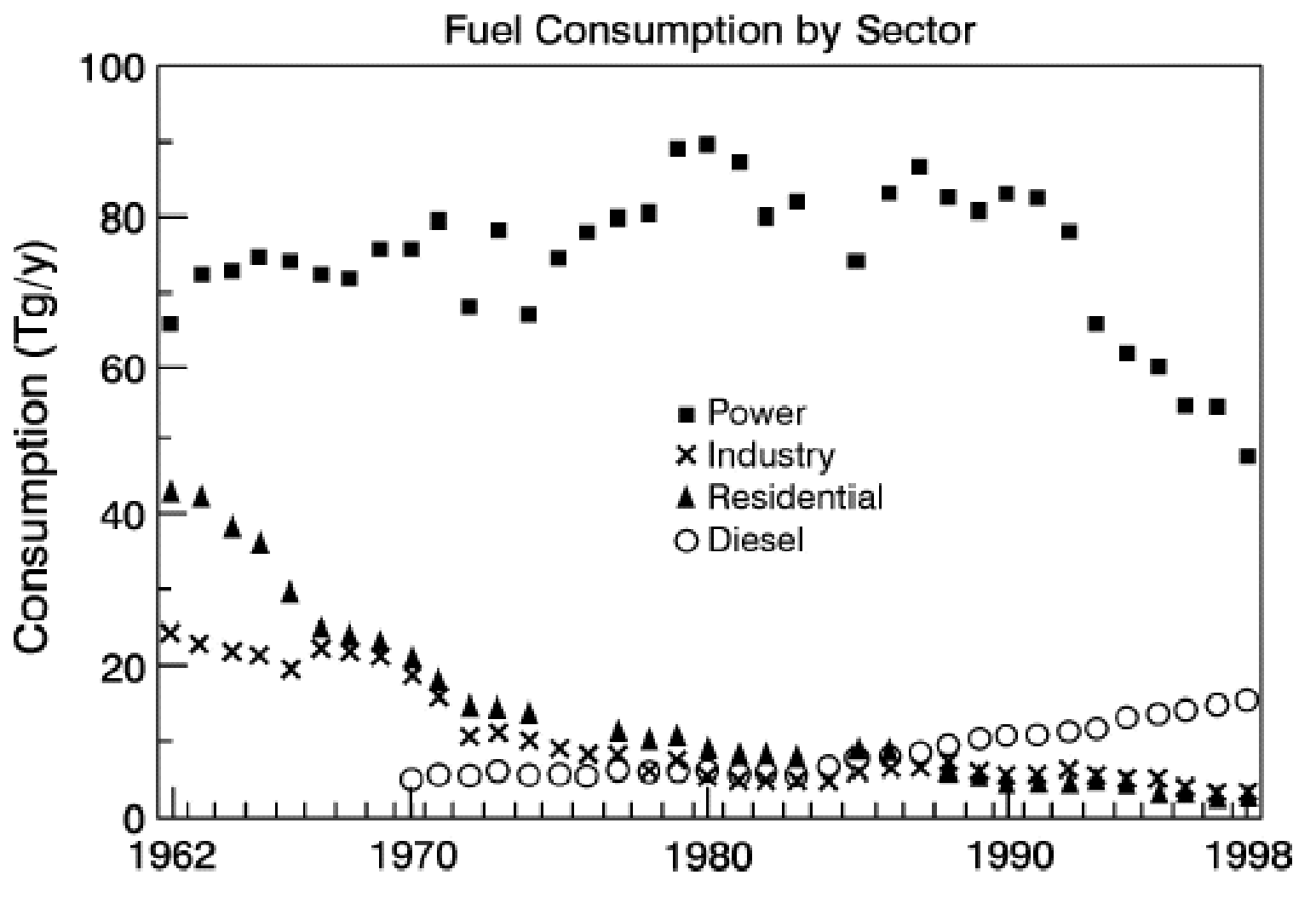

Fig. 4 

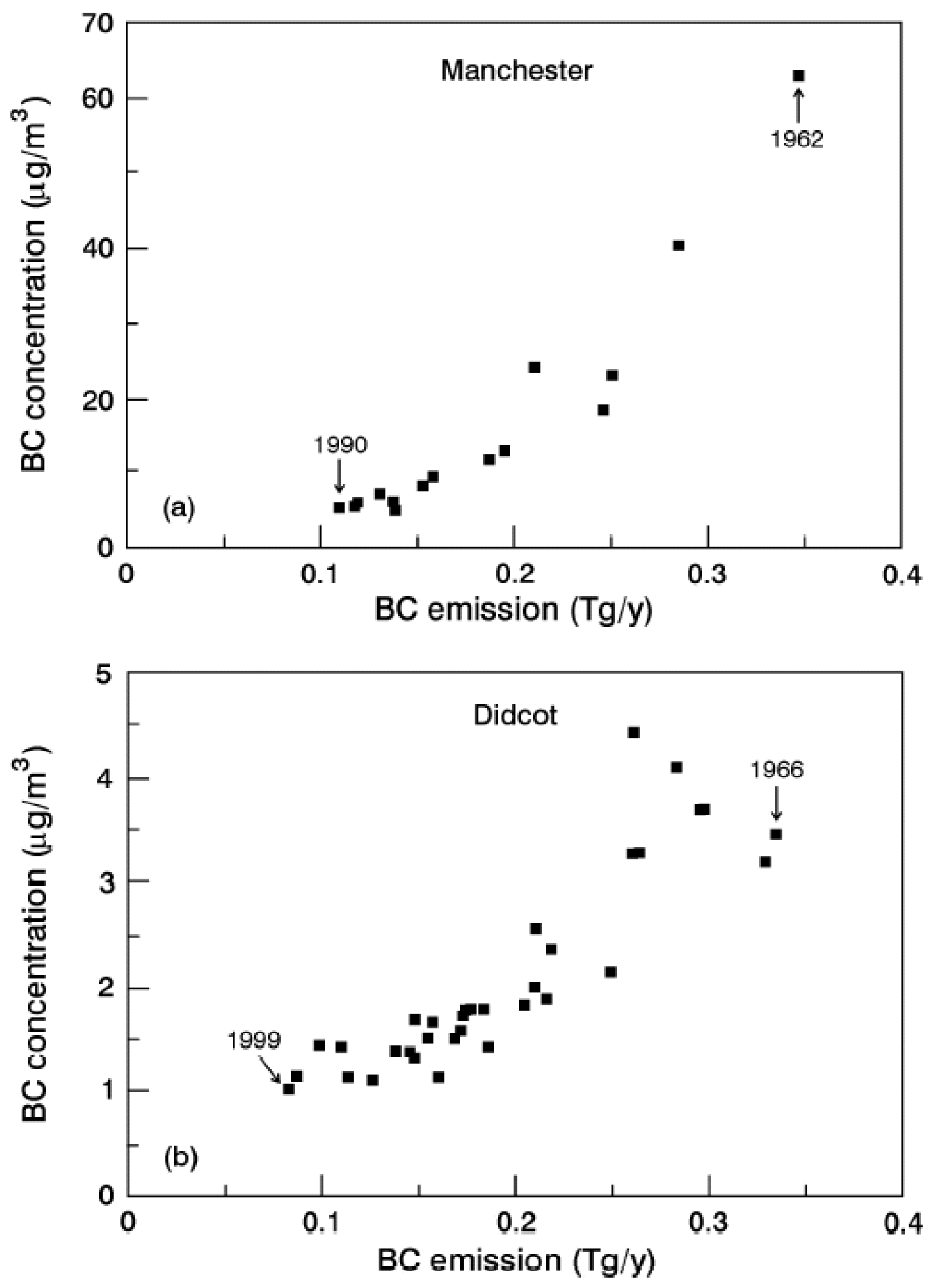

Fig. 5 

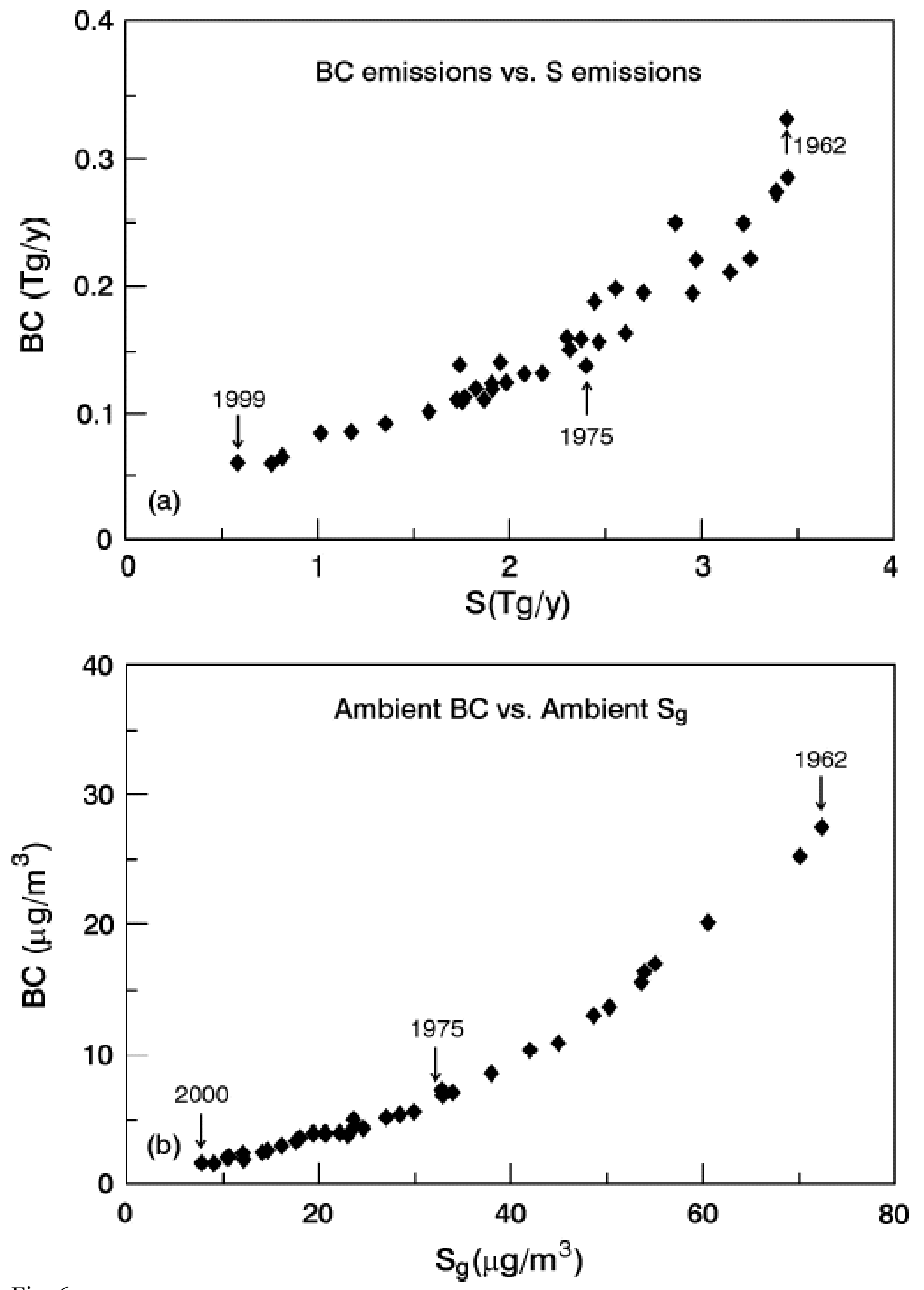

Fig. 6 

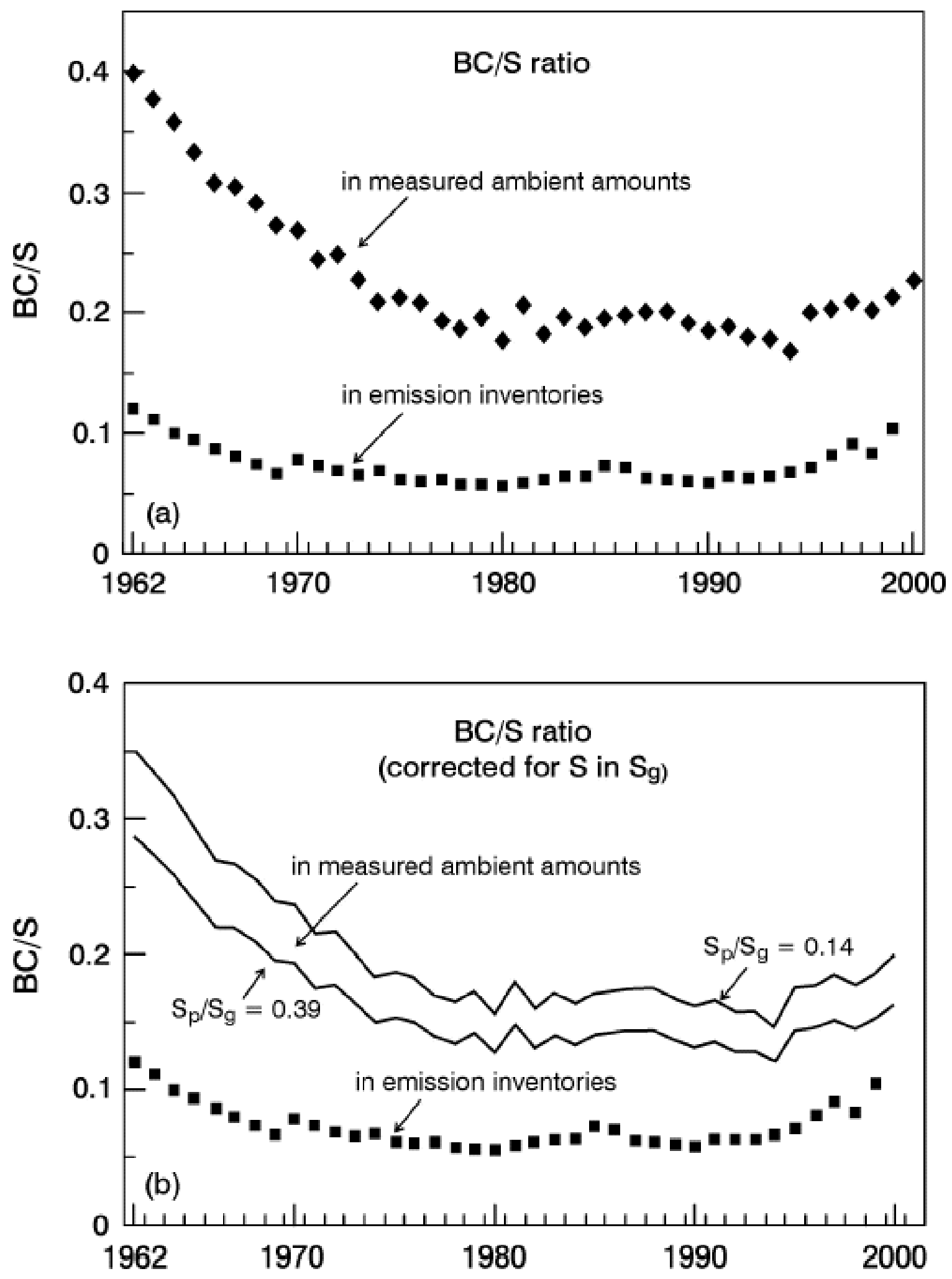

Fig. 7 